\title{
Using sticky ideas to promote reproductive health literacy: the reproductive anatomy tool kit(C)
}

\section{Introduction}

Healthy People $2020^{1}$ goals for reducing unintended pregnancy focus largely on promoting access to contraception but there are underlying issues of reproductive literacy that need to be addressed as well. ${ }^{2}$ Traditional sex education is frequently fear-based, preachy, and boring. Instructors, keenly aware of societal taboos, tend to rely heavily on technical medical information as a way to reduce discomfort with the subject. This trap, known as the "curse of knowledge", results in a tendency for content to get so steeped in the accuracy of details that the core messages are lost. ${ }^{3}$ Rather than positively informing, this approach too often diminishes connection, discourages mindfulness and undermines personal empowerment about sexuality.

Our innovative approach uses a holistic triad consisting of sticky messages, normalization, and connection that is powerful in its simplicity. The elements of the triad are not meant to function independently. Instead, they complement and influence one another creating dynamic interconnections. Sticky messages use humor, everyday language, simple analogies, and concrete metaphors to make complicated reproductive facts easily understood. ${ }^{3}$ Core messages "stick" and are retained because they are tied to familiar concepts individuals already know. Normalization shifts the focus away from shame, taboos, and fear-based messages that have had little success in reducing HIV transmission, sexually transmitted infections (STIs), unintended pregnancies, and misuse or nonuse of contraception. ${ }^{4}$ Connection is promoted by replacing preachy "you" messages with empowering "we" messages that transcend race, class, gender, ethnicity and religion. "We" messages normalize and promote positive energy by allowing people to feel seen, heard, and valued without judgment - the essence of connection. Because our approach is both innovative and holistic, it is more likely to promote reproductive and sexual literacy and open and honest communication. These outcomes, in combination, empower people to adopt behaviors that increase contraceptive use and safe sex practices, keys to reducing unplanned pregnancies and infections. A powerful example of these principles is the Reproductive Anatomy Tool $\mathrm{Kit}^{\mathrm{Q}}$.

\section{Case presentation/description/purpose}

The tool kit for teaching anatomy and physiology has been designed by Linda Robinson, advanced nurse practitioner, and is created from simple everyday items. The kit exemplifies and explains anatomy by using a simple unexpected, concrete, credible, and emotional (funny, whimsical) story to depict how the human reproductive system works. The message is shifted from dramatizing sex to normalizing sex, and veers away from the fear-based messages that have not had much success in reducing unplanned pregnancies or sexually transmitted infections. The everyday items are housed in a basic plastic tool box that contains:

i. Tampon/sanitary pad (visible sign that baby-making machine is turned on),

ii. Bird nest (uterus),

iii. Egg carton (ovary),
Volume 5 Issue 3 - 2017

\author{
Kathryn J Luchok,' Linda Robinson ${ }^{2}$ \\ 'Department of Anthropology and Women's and Gender \\ Studies, University of South Carolina, USA \\ ${ }^{2}$ APRN-BC, Women's Health Consultant, USA
}

Correspondence: Kathryn Luchok, Research Professor, Ph.D., Department of Anthropology and Women's and Gender Studies, University of South Carolina, Columbia, South Carolina, USA, Tel 803-777-4200,Email luchok@mailbox.sc.edu

Received: June 02, 2017 | Published: July 10, 2017

iv. Plastic eggs (ova),

v. Straws (fallopian tubes),

vi. Empty toilet paper roll (vagina),

vii. Red shredded party paper (menstrual blood),

viii. Penis model / turkey baster (semen injector),

ix. White hand cream mixed with water (semen),

x. Liter bottle filled with sand (350 million sperm),

xi. Teaspoon (average amount of ejaculate),

xii. Funnel (refill liter bottle),

xiii. Newspaper (dumping sand),

xiv. Trash bag (demonstrates where waste/toxic junk goes),

xv. Condoms (demonstrates where non-reproductive junk goes),

xvi. M\&M bag to demonstrate the M\&M years (menses to menopauselength of time the female baby-making is working- 40 plus yearshow many machines last that long?),

xvii. Remote Control (contraception pauses the baby-making machine),

xviii. Pine Sol bottle (what would be coming out if menstruation was to clean you out!).

\section{Intended audience}

The Reproductive Anatomy Tool Kit can be used with a variety of audiences. It can be used by any professional or paraprofessional who needs to explain the reproductive system to a client or a group of clients, including nurses, doctors, physician assistants, health educators, teachers, peer educators, nursing, medical and public health students, parents. It is easily disseminated since anyone can build a kit using basic household supplies, and individuals can add items as they see fit. It works equally well with adults and children/teens. 


\section{Health behavior}

The Tool Kit is used to promote reproductive literacy by demystifying and normalizing sex and the reproductive system so that women and men understand their basic systems. This is the first step in taking control of their reproductive destinies, and opens the door to explaining about how to avoid unplanned pregnancy and STIs/HIV/ AIDS.

\section{Developed}

This kit was derived from over 15years of clinical practice serving thousands of patients-finding new ways to reach patients to promote better reproductive health. It also incorporated elements from other sources, such as the work of Amy Schalet on normalizing sex. Already intuitively using "sticky" ideas, the work of Chip and Dan Heath et al. $^{3}$

\section{Made to stick}

Why some ideas survive and others die, Random House) helped to put an explanatory framework around the innovative methods for talking about reproduction in a way audiences could easily grasp and understand.

\section{Evaluated}

After each training workshop the participants filled out an assessment form. 6months post training they did a Survey Monkey survey to test retention and use of the material. Across the 15 workshops, 99\% state they learned something new and useful, $98 \%$ say they are confident in their understanding of the material, and $94 \%$ say they plan to use the material with their clients. $100 \%$ are satisfied with the training. Six months post training, $99 \%$ say they use the material, $94 \%$ retain the knowledge base, and $94 \%$ say they have a better understanding of reproductive anatomy.

In open ended responses, participants report: "It changed my approach to home visitation...I have officially joined the women's health movement; "I finally have a way to talk to my clients and my own daughter about sex in a way they will understand."; "Since attending your training and incorporating your teaching methods, family planning has gone from least to most favorite topic for our clients."

\section{Acknowledgements}

None.

\section{Conflict of interest}

The author declares no conflict of interest.

\section{References}

1. Family Planning. Office of Disease Prevention and Health Promotion, USA; 2017.

2. Taylor D, Levi A, Simmonds K. Reframing unintended pregnancy prevention: a public health model. Contraception. 2010;81(1):363-366.

3. Heath C, Heath D. Made to stick: Why some ideas survive and others die. USA: Random House; 2008.

4. Schalet A. Beyond abstinence and risk: A new paradigm for adolescent sexual health. Women's Health Issues. 2011;21(3 Suppl):S5-S7.

5. Brown B. The power of vulnerability: Teachings on authenticity, connection, and courage. USA: Sounds True; 2012. 